\title{
Nanoparticle-Enhanced Fluorescence Imaging of Latent Fingerprints Reveals Drug Abuse
}

\author{
Otto S. Wolfbeis*
}

drug detection · fluorescence $\cdot$ imaging agents

immunoassays $\cdot$ nanoparticles

$T_{\text {he ridge pattern of skin on the human finger produces a }}$ unique fingerprint. ${ }^{[1]}$ Sweat is excreted through the pores in the skin and deposited on the surface of the skin, from where it can be transferred to another surface to leave an impression of the ridge pattern. This impression is referred to as a latent fingerprint (LFP), the detection and identification of which is an indispensable tool in forensic science. ${ }^{[1,2]}$ LFPs can be visualized by conventional means ${ }^{[1]}$ but also by using various nano- and microparticles. ${ }^{[3]}$ LFPs also can be visualized by applying reagents that are capable of generating color or fluorescence. ${ }^{[4]}$ LFPs also display native fluorescence, ${ }^{[5]}$ mainly in the UV region. This fluorescence is the result of the presence of various fluorescent biomolecules in sweat, which may also contain orally ingested and metabolized drugs.

While diagnostic assays have been applied to various kinds of bodily fluids including blood, serum, urine, saliva, interstitial and brain fluids, and even to fluids that are obtained by condensation of organic molecules contained in the breath, diagnostic methods based on the analysis of sweat (also in LFPs) have not been used to a large extent. This is surprising, as it is known that sweat contains a variety of metabolites of clinical significance. Apart from the potential of LFPs to serve as "samples" for use in medical diagnosis, there is substantial interest in the use of LFPs for the detection of illicit drugs and explosives. Various methods such as fluorescence and Raman spectroscopy have been applied to detect these species. ${ }^{[6]}$ The detection of a drug in a fingerprint may indicate that an individual has come into contact with a drug, but this does not necessarily prove the (ab)use of a drug, as it cannot be excluded that the drug was deposited on the LFP at a certain time after it had been generated.

An elegant solution to this problem has been presented in two recent reports by Russell et al. ${ }^{[7]}$ The authors combine three kinds of high technology, namely 1) magnetic nanoparticles, 2) fluorescence imaging, and 3) immunoassay, to produce a method that has a high potential not only for the detection of various kinds of drugs, but also for the detection of other species such as chemicals formed in explosions.

[*] Prof. O. S. Wolfbeis

Institute of Analytical Chemistry, Chemo- and Biosensors

University of Regensburg, 93040 Regensburg (Germany)

E-mail: Otto.Wolfbeis@chemie.uni-r.de

Homepage: http://www.wolfbeis.de
In their first report ${ }^{[7 a]}$ modified gold nanoparticles (NPs) were used to detect cotinine, a metabolite of nicotine. The multiple anticotinine antibodies were functionalized with gold NPs to obtain considerable signal and contrast enhancements in the detection of the specific interaction between the antibody and the cotinine in the LFP. Gold NPs were first surface-tagged with protein $\mathrm{A}$, which acts as a second linker for immobilization of anticotinine antibodies. Protein A was chosen as it exerts a positive effect on the orientation of the antibody when binding to the protein. A solution containing the anticotinine antibody/NP conjugates was pipetted onto the fingerprints of a smoker, incubated for 10 minutes, and the unbound nanoparticles were removed by washing. Subsequently, a fluorescently tagged secondary antibody fragment was placed on the fingerprint. The secondary antibody only binds to sites where cotinine is present. After removal of excess reagents, the LFPs were imaged and compared to images obtained from LFPs of nonsmokers. The presence of cotinine could be easily detected in the LFPs of smokers. When experiments were performed with antibodies not bound to gold NPs, the quality of the images remained poor and did not enable identification of the person who had deposited the fingerprints.

In the second approach (outlined in Scheme 1) ${ }^{[\mathrm{bb}]} \mathrm{mag}$ netic NPs were applied rather than gold NPs. Again, primary antibodies (against drug metabolites) were conjugated to magnetic NPs that, in this case, were coated with a recombinant fusion protein $\mathrm{A} / \mathrm{G}$. The magnetic particles were then deposited to incubate the LFP, removed with a magnetic brush (except, of course, for those particles that were bound to the antigen), treated with a (fluorescently tagged) secondary antibody fragment, and incubated again for 30 minutes. After washing, the LFP was then characterized by fluorescence imaging.

In a typical example, an LFP containing benzoylecgonine (BzECG), the major metabolite of cocaine, was treated as described above. Figure 1 shows a pair of images obtained in this way; Figure $1 \mathrm{a}$ and Figure $1 \mathrm{~b}$ are the brightfield and fluorescence images, respectively, of such an LFP. The red fluorescence of the magnetic NPs labeled with a fluorescent secondary antibody is clearly visible (the pictures also reveal higher-level details that will not be discussed herein). This observation is consistent with previous reports of the capability of NPs to strongly enhance fluorescence signals. ${ }^{[8]}$ No red fluorescence was observed in the LFPs of volunteers who 


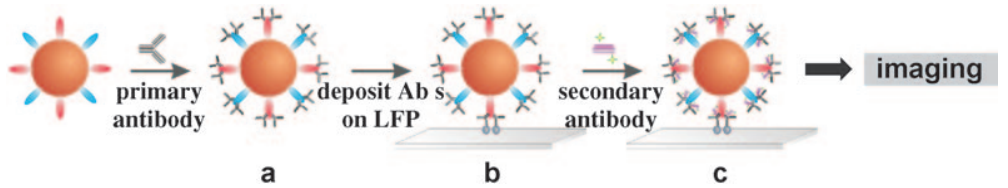

species, if properly condensed on a solid support or matrix, and if antibodies are available, may be detected by using the same imaging techniques.

Published online: February 4, 2009

Scheme 1. Detection of drugs and metabolites by using antibody-magnetic-particle conjugates. a) Protein A/G coated magnetic particles were combined with a primary antibody to prepare the antibody-functionalized magnetic particle conjugates. b) The conjugates were incubated over a latent fingerprint (LFP) that had been collected on a glass microscope slide. Excess particles were removed using a magnet. c) A secondary antibody fragment tagged with a red label was incubated over the fingerprint. After washing, the fingerprint was imaged by using a stereomicroscope.

a)

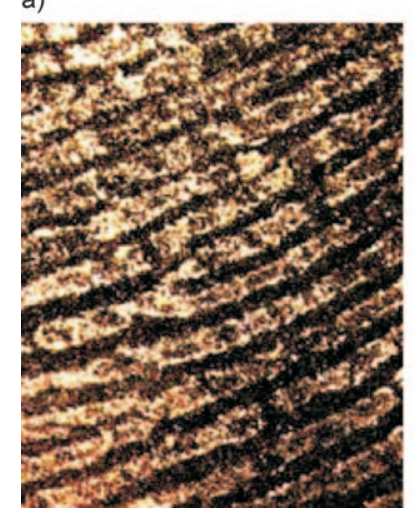

b)

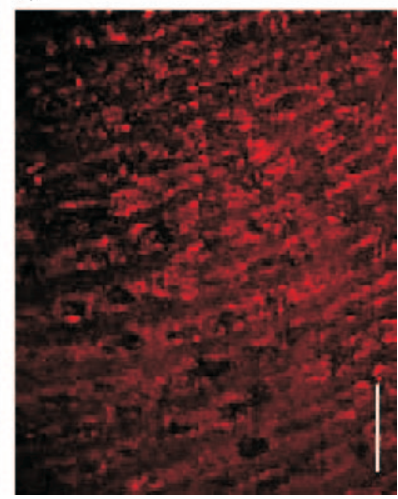

Figure 1. Detection of benzoylecgonine in a fingerprint. a) Brightfield and b) fluorescence images of a section of a latent fingerprint after incubation of antibenzoylecgonine-antibody-functionalized magnetic particles and a secondary antibody displaying red fluorescence. Scale bars: $1 \mathrm{~mm}$.

were not taking any drugs. The example shown here demonstrates the successful application of the technique, as BzECG has a rather short half-life in sweat and can be difficult to detect. Other metabolites, such as those of tetrahydrocannabinol (marijuana), methadone (a synthetic opioid), and one of its metabolites, gave distinctly better images.

The described method is sufficiently simple and has a high potential in that it may not only serve to detect metabolites of nicotine and illicit drugs, but also chemical products of explosions, metabolic species that can act as diagnostic markers, and possibly also hormones (so that visits to a fitness studio could be combined with a health or pregnancy test). It may be extended-with some added technology such as short tandem repeat (STR) typing-to other species, possibly even RNA and DNA. ${ }^{[8]}$ In terms of instrumentation, multiplex detection (one color or one fluorescence lifetime for each analyte) could be easily accomplished by using NPs. ${ }^{[10]}$ Finally, the approach is not limited to fingerprints: over 1000 organic species have been detected in the air exhaled by humans to date. Conceivably, some of these
[1] a) R. Saferstein, Criminalistics: An Introduction to Forensic Science, Prentice Hall, London, 2001; b) M. J. Choi, A. M. McDonagh, P. Maynard, C. Roux, Forensic Sci. Int. 2008, 179, 87-97; c) H. C. Lee, R. E. Gaensslen, Advances in Fingerprint Technology, CRC, Boca Raton, FL, 2004; d) Encyclopedia of Analytical Chemistry (Ed.: R. A. Meyers), Wiley, New York, 2001.

[2] K. K. Bouldin, PhD Thesis, Texas Tech University, Lubbock, Texas, USA; 2003; http://etd.lib.ttu.edu/theses/ available/etd-06272008-31295017090514/unrestricted/ 31295017090514.pdf (accessed in Nov. 2008; contains an excellent overview on the topic).

[3] a) M. Sametband, I. Shweky, U. Banin, D. Mandler, J. Almog, Chem. Commun. 2007, 1142-1144; b) M. J. Choi, K. E. McBean, P. H. R. Ng, A. M. McDonagh, P. J. Maynard, C. Lennard, C. Roux, J. Mater. Sci. 2008, 43, 732-737; c) E. R. Menzel, S. M. Savoy, S. J. Ulvick, K. H. Cheng, R. H. Murdock, M. R. Sudduth, J. Forensic Sci. 2000, 45, 545-551; d) B. J. Theaker, K. E. Hudson, F. J. Rowell, Forensic Sci. Int. 2008, 174, 26-34; e) M. J. Choi, T. Smoother, A. A. Martin, A. M. McDonagh, P. J. Maynard, C. Lennard, C. Roux, Forensic Sci. Int. 2007, 173, $154-160$.

[4] a) L. K. Seah, U. S. Dinish, S. K. Ong, Z.X. Chao, V. M. Murukeshan, Opt. Laser Technol. 2004, 36, 371-376; b) U. S. Dinish, Z. X. Chao, L. K. Seah, V. M. Murukeshan, Int. J. Nanosci. 2005, 4, 695-700; c) N. Saitoh, N. Akiba, TheScientificWorld 2005, 5, 355-366; d) R. D. Roorda, A. C. Ribes, S. Damaskinos, A. E. Dixon, E. R. Menzel, J. Forensic Sci. 2000, 45, $563-567$.

[5] a) D. B. Hansen, M. M. Joullié, Chem. Soc. Rev. 2005, 34, 408417; b) I. Alaoui, E. R. Menzel, M. Farag, K. Cheng, R. Murdock, Forensic Sci. Int. 2005, 152, 215-219; c) J. Almog, G. Levinton-Shamuilov, Y. Cohen, M. Azoury, J. Forensic Sci. 2007, $52,330-334$.

[6] a) J. S. Day, H. G. M. Edwards, S. A. Dobrowski, A. M. Voice, Spectrochim. Acta Part A 2004, 60, 1725-1730; b) R. Leggett, E. E. Lee-Smith, S. M. Jickells, D. A. Russell, Spectrochim. Acta Part A 2004, 60, 563-568; c) M. J. West, M. J. Went, Spectrochim. Acta Part A 2009, 71, 1984-1988; d) M. J. West, M. J. Went, Forensic Sci. Int. 2008, 174, 1-5.

[7] a) R. Leggett, E. E. Lee-Smith, S. M. Jickells, D. A. Russell, Angew. Chem. 2007, 119, 4178-4181; Angew. Chem. Int. Ed. 2007, 46, 4100-4103; b) P. Hazarika, S. M. Jickells, K. Wolff, D. A. Russell, Angew. Chem. 2008, 120, 10321-10324; Angew. Chem. Int. Ed. 2008, 47, 10167-10170.

[8] S. Nagl, M. Schaeferling, O. Wolfbeis, Microchim. Acta 2005, 151, $1-21$.

[9] a) P. H. Yu, M. M. Wallace, Forensic Sci. Int. 2007, 168, 112-118; b) C. J. Fregeau, O. Germain, R. M. Fourney, J. Forensic Sci. 2000, 45, 26; c) M. K. Balogh, J. Burger, K. Bender, P. M. Schneider, K. W. Alt, Forensic Sci. Int. 2003, 137, 188-195.

[10] J. M. Kürner, I. Klimant, Ch. Krause, E. Pringsheim, O. S. Wolfbeis, Anal. Biochem. 2001, 297, $32-41$. 